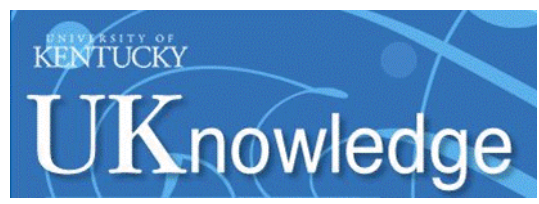

University of Kentucky

UKnowledge

$11-2015$

\title{
Results of a Health Education Message Intervention on HPV Knowledge and Receipt of Follow-up Care among Latinas Infected with High-Risk Human Papillomavirus
}

\author{
Maureen Sanderson \\ Meharry Medical College \\ Dineo Khabele \\ Vanderbilt University \\ Claudine L. Brown \\ Meharry Medical College \\ Khalil Harbi \\ Meharry Medical College \\ Leah R. Alexander \\ Meharry Medical College \\ Follow this and additional works at: https://uknowledge.uky.edu/obgyn_facpub \\ see next of the Pagstetrifis and Gynecology Commons \\ Right click to open a feedback form in a new tab to let us know how this document benefits you.
}

\section{Repository Citation}

Sanderson, Maureen; Khabele, Dineo; Brown, Claudine L.; Harbi, Khalil; Alexander, Leah R.; Coker, Ann L.; Fernandez, Maria E.; Brandt, Heather M.; Fadden, Mary K.; and Hull, Pamela C., "Results of a Health Education Message Intervention on HPV Knowledge and Receipt of Follow-up Care among Latinas Infected with High-Risk Human Papillomavirus" (2015). Obstetrics and Gynecology Faculty Publications. 9. https://uknowledge.uky.edu/obgyn_facpub/9

This Article is brought to you for free and open access by the Obstetrics and Gynecology at UKnowledge. It has been accepted for inclusion in Obstetrics and Gynecology Faculty Publications by an authorized administrator of UKnowledge. For more information, please contact UKnowledge@lsv.uky.edu. 


\section{Results of a Health Education Message Intervention on HPV Knowledge and Receipt of Follow-up Care among Latinas Infected with High-Risk Human}

Papillomavirus

Digital Object Identifier (DOI)

http://dx.doi.org/10.1353/hpu.2015.0131

Notes/Citation Information

Published in Journal of Health Care for the Poor and Underserved, v. 26, no. 4, p. 1440-1455.

Copyright ( 2015 The Johns Hopkins University Press. This article first appeared in Journal of Health Care for the Poor and Underserved, Volume 26, Issue 4, November, 2015, pages 1440-1455.

\section{Authors}

Maureen Sanderson, Dineo Khabele, Claudine L. Brown, Khalil Harbi, Leah R. Alexander, Ann L. Coker, Maria E. Fernandez, Heather M. Brandt, Mary K. Fadden, and Pamela C. Hull 


\title{
Results of a Health Education Message Intervention on HPV Knowledge and Receipt of Follow-up Care among Latinas Infected with High-risk Human Papillomavirus
}

\author{
Maureen Sanderson, $\mathrm{PhD}$ \\ Dineo Khabele, MD \\ Claudine L. Brown, MD, MSPH \\ Khalil Harbi, MD, MSPH \\ Leah R. Alexander, PhD, MPH \\ Ann L. Coker, PhD \\ Maria E. Fernandez, $\mathrm{PhD}$ \\ Heather M. Brandt, PhD \\ Mary K. Fadden, PA-C, MPH \\ Pamela C. Hull, PhD
}

\begin{abstract}
A clinic-based intervention study was conducted among high-risk human papillomavirus (HPV)-infected Latinas aged 18-64 years between April 2006 and May 2008 on the Texas-Mexico border. Women were randomly assigned to receive a printed material intervention $(n=186)$ or usual care $(n=187)$ and were followed at three months, six months, and 12 months through telephone surveys and review of medical records. The HPV knowledge of nearly all women had increased greatly, but only two-thirds of women reported they had received follow-up care within one year of diagnosis regardless of additional health education messaging. Our findings suggest that, regardless of type of health education messaging, Latinas living on the Texas-Mexico border are aware that follow-up care
\end{abstract}

\footnotetext{
MAUREEN SANDERSON is associated with the School of Graduate Studies and Research Meharry Medical College, Nashville, TN and the Department of Family and Community Medicine, Meharry Medical College, Nashville, TN. DINEO KHABELE is associated with the Departments of Obstetrics and Gynecology and Cancer Biology, Vanderbilt University Medical Center, Nashville, TN. CLAUDINE L. BROWN, KHALIL HARBI, and LEAH ALEXANDER is associated with the School of Graduate Studies and Research, Meharry Medical College, Nashville, TN. ANN L. COKER is associated with the Department of Obstetrics and Gynecology and Epidemiology, University of Kentucky, Lexington, KY. MARIA E. FERNANDEZ is associated with the Division of Health Promotion and Behavioral Sciences, University of Texas Health Science Center at Houston School of Public Health, Houston, TX and the Department of Family and Community Medicine, Meharry Medical College, Nashville, TN. HEATHER M. BRANDT is associated with the Department of Health Promotion, Education and Behavior. MARY K. FADDEN is associated with the University of South Carolina Arnold School of Public Health, Columbia, SC. PAM C. HULL is associated with the Division of Epidemiology, Vanderbilt University Medical Center, Nashville, TN. Correspondence can be sent to Dr. Maureen Sanderson, Department of Family and Community Medicine, Meharry Medical College, 1005 Dr. D.B. Todd Jr. Blvd., Nashville, TN 37208, Phone: 615-321-2977, Fax: 615-327-6296, E-mail: msanderson@mmc.edu
} 
is recommended, but they may not receive this care. Individual, familial and medical care barriers to receipt of follow-up care may partially account for the higher rates of cervical cancer mortality in this region.

Key words: Follow-up care, HPV, Latina, intervention study.

$\mathrm{P}$ ersistent infection with two high-risk types of human papillomavirus (HPV-16 and/or HPV-18) is known to cause $70 \%$ of cervical cancers. ${ }^{1}$ Despite increases in cervical cancer screening in the past few decades, Latinas have substantially higher rates of cervical cancer mortality than non-Hispanic White women. ${ }^{2}$ Although a vaccine to protect against these high-risk HPV types was released in 2006, it is not available to older women and cervical cancer screening is still recommended for women who receive the vaccine. ${ }^{3}$ The decline in cervical cancer mortality rates seen since the 1950 s that was attributed to increased cervical cancer screening has leveled off and was stable from 2007 to $2011 .{ }^{4}$ Latinas continue to experience higher rates of cervical cancer mortality than non-Hispanic Whites due to lower rates of cervical cancer screening and poor adherence to follow-up care after abnormal Pap tests. ${ }^{5}$ As many as $80 \%$ of cervical cancer deaths could be averted through appropriate screening and follow-up care. ${ }^{6}$

From 1997-2006, Latinas living on the Texas border had a 31\% higher cervical cancer mortality rate than non-border Latinas in Texas. ${ }^{7}$ A possible explanation for this disparity is the failure of border Latinas to receive Pap tests ${ }^{8}$ or to receive appropriate follow-up care after abnormal Pap tests. ${ }^{9}$

The objective of the present study was to evaluate the effect of a health messaging intervention on receipt of follow-up care among high-risk HPV infected Latinas living on the Texas-Mexico border. Follow-up care was based on women's reports of their health care providers' recommendations at baseline for follow-up diagnostic procedures, treatments and recommendations. Latinas newly diagnosed with high-risk HPV were randomized to receive a printed health education material intervention in the form of an HPV educational brochure developed by the Centers for Disease Control and Prevention (CDC). We hypothesized that Latinas who received the HPV brochure would have 1) increased knowledge of HPV, and 2) more timely receipt of follow-up care after a high-risk HPV diagnosis than Latinas randomized to receive usual care.

\section{Methods}

Conceptual framework. Our conceptual framework was based on a combination of health behavior theories and constructs such as the Theory of Planned Behavior, ${ }^{10-12}$ the Health Belief Model, ${ }^{10}$ and self-efficacy. ${ }^{11-12}$ Certain attitudes and perceptions influence behavioral intention, and ultimately the behavior of interest. The model shows how the woman, provider, and environmental factors interact.

Study design. We conducted a clinic-based intervention study to examine a health education message intervention between April 2006 and May 2008. Inclusion criteria were: Latinas aged 18-64 years living on the Texas-Mexico border who were diagnosed with high-risk HPV through Hybrid Capture 2 with no history of treatment for an abnormal Pap test. Clinic providers identified women shortly after diagnosis and prior 


\section{Supplementary Table 1.}

RESPONSE RATES TO QUANTITATIVE SURVEYS ${ }^{a}$

\begin{tabular}{|c|c|c|c|c|c|c|c|c|}
\hline \multirow[b]{2}{*}{ Response } & \multicolumn{2}{|c|}{$\begin{array}{l}\text { Baseline } \\
(n=518)\end{array}$} & \multicolumn{2}{|c|}{$\begin{array}{l}\text { 3-month } \\
(n=460)\end{array}$} & \multicolumn{2}{|c|}{$\begin{array}{l}\text { 6-month } \\
(n=460)\end{array}$} & \multicolumn{2}{|c|}{$\begin{array}{c}\text { 12-month } \\
(\mathrm{n}=460)\end{array}$} \\
\hline & $\mathbf{n}$ & $\%$ & $\mathbf{n}$ & $\%$ & & & & \\
\hline Refused & 55 & 10.6 & 15 & 3.3 & 4 & 0.9 & 3 & 0.7 \\
\hline Lost to follow-up & 3 & 0.6 & 36 & 7.8 & 24 & 5.2 & 43 & 9.3 \\
\hline Insufficient time & - & & 44 & 9.6 & 102 & 22.2 & 198 & 43.0 \\
\hline Completed & 460 & 88.8 & 365 & 79.3 & 330 & 71.7 & 216 & 47.0 \\
\hline
\end{tabular}

${ }^{a}$ Of the 373 women included in the present analysis, 191 women completed 3 follow-up surveys (51.2\%), 111 women completed 2 follow-up surveys (29.8\%), and 71 women completed 1 follow-up survey $(19.0 \%)$.

to treatment. The majority of participants were recruited from the dysplasia clinic that provided diagnosis and treatment for women participating in the Texas Breast and Cervical Cancer Screening Program. A total of 460 women were recruited and interviewed in the clinic shortly after their HPV diagnosis had been explained to them by their provider (88.8\% response rate) (Supplementary Table 1). After the baseline survey, all women had the opportunity to ask HPV questions, which interviewers were trained to answer using a list of responses developed by our study gynecologic oncologist (CDA); women were told to ask their providers questions that did not appear on the list. Of the 460 women completing the baseline survey, 130 women asked the interviewer a question (broken down by 71 in the intervention and 59 in the control group). Half of the women $(n=186)$ were randomly selected to receive an eight-page CDC-developed HPV educational brochure level available in English and Spanish, and the other half of women $(n=187)$ received usual care. The sample size required to detect a 0.15 rate difference at a 0.05 significance level with $80 \%$ power was 176 participants per group.

Detailed methods of the brochure development have appeared elsewhere. ${ }^{13}$ Briefly, in February 2005 two different brochures were tested with 15 focus groups of White, African American, and Hispanic individuals with less than a college education between ages 18 and 29, who were low-income and currently or planning to become sexually active. The focus groups were stratified by gender, race/ethnicity, language and geography and the final brochure was geared toward an 8th grade reading level. The brochure covered the following topics: 1) Why haven't more people heard of genital HPV? 2) How common is genital HPV? 3) Who gets genital HPV? 4) What makes a person more likely to get HPV? 5) What does "low-risk" HPV mean? 6) What does "high-risk" HPV mean? 6) Does "high-risk" HPV mean cancer? 7) How can women prevent cervical cancer? 8) Why should women get regular Pap tests? 9) Should women worry about abnormal Pap test results? 10) What about a HPV test for women? 11) What's the dif- 
ference between the Pap test and the HPV test? 12) Do I need to know if I have genital HPV? 13) Is there a cure for genital HPV? 14) Are there ways to reduce my chances of getting genital HPV? 15) What are condoms? 16) What about a vaccine? The content was similar to that of brochures produced by Krames, Planned Parenthood, American College of Obstetricians and Gynecologists, Merck, and county health departments. The present analysis is restricted to women who identified themselves as Latina who completed at least one follow-up survey $(n=373)$.

Data gathered from our formative research were used to develop the baseline and follow-up patient surveys which covered HPV knowledge, reaction to an abnormal Pap or HPV diagnosis, and patient-provider communication. Our formative research consisted of in-depth personal interviews with 44 women recently diagnosed with a positive high-risk HPV test; ${ }^{14}$ focus groups with 30 women and 11 men on HPV knowledge, attitudes and beliefs; ${ }^{15}$ and in-depth telephone interviews with 26 women's health care providers. Follow-up telephone surveys were designed to determine whether women had received follow-up care and to assess whether women retained information provided to them during their baseline survey. Medical records were also abstracted for information on receipt of follow-up care.

HPV knowledge, attitudes, and beliefs indices reported during baseline survey. Based on prior formative research, we developed an HPV knowledge index that was a summation of the total number of correct responses to 13 questions such as "Can human papillomavirus be spread by sex?" answered by women who indicated they had heard of HPV during the baseline survey. The 144 women who had not heard of HPV were assigned a 0 . Two subscales (one consisting of nine items and one with six items) were used to assess HPV attitudes. For the nine-item subscale, participants who responded to questions such as "As a result of your abnormal Pap or HPV test results, how much do you feel stressed?" with "very much/somewhat" were coded 0 and "just a little/not at all" were coded 1. For the six-item subscale, participants who indicated they had told someone of their diagnosis and responded to questions such as "Most people have been supportive after hearing that you have HPV" with "strongly agree/ agree" were coded 1 and "undecided/disagree/strongly disagree" were coded 0 . A total of 59 women who indicated they had not told anyone of their diagnosis were assigned a 0 for this subscale.

A 10-item HPV beliefs index was created in which participants who responded to questions such as "Having HPV makes me more aware of my health," with "strongly agree/agree" were coded 1 and "undecided/disagree/strongly disagree" were coded 0 . Scale items were reverse-coded as needed. The approximate median was used to dichotomize these indices as high or low since they were developed by our team and had not been validated.

Recommended follow-up care reported during baseline survey. Women's reports of their health care providers' recommendations at baseline for follow-up diagnostic procedures, treatments and recommendations were in response to the question "Which one(s) of the following things did your health care provider tell you to do because of your abnormal Pap or HPV diagnosis?" We grouped the categories "Have a colposcopy/ Have a test that takes a closer look at your cervix" and "Have a biopsy" as one diag- 
nostic procedure. The other diagnostic procedure was "Have another Pap smear." The categories "Have cryotherapy (freezing)" and "Have some other kind of treatment (loop electrosurgical excision procedure [LEEP] or laser)" were grouped as treatment. Women who responded "Other" and specified the other recommendation were recoded into appropriate categories.

Knowledge of HPV and receipt of follow-up care reported during follow-up survey. Knowledge of HPV at follow-up was based on the HPV knowledge index detailed previously and answered by all women. Women who correctly answered any of the 13 items during a particular follow-up survey were given credit for a correct response for that survey only. Receipt of follow-up care was based on women's self-report of diagnostic procedures or cryotherapy/other treatment in response to the question, "Which of the following things have you done since the last time we talked because of your HPV diagnosis?" Women who responded that they had received diagnostic procedures or cryotherapy/other treatment during any of the follow-up surveys were considered as having received follow-up care overall.

Statistical analysis. The statistical analysis for this paper was generated using SAS 9.2 software (Copyright, SAS Institute Inc. SAS and all other SAS Institute Inc. product or service names are registered trademarks or trademarks of SAS Institute Inc., Cary, NC, USA). Chi-square was used to compare the baseline demographic and HPV characteristics of women randomized to receive the HPV brochure or usual care to assess the success of our randomization. Chi-square was also used to characterize the patient recall of recommended follow-up care reported at baseline by type of intervention. We used generalized estimating equations (GEE) to estimate the rate ratios (RR) for type of health education messaging received at baseline and self-reported knowledge of HPV and receipt of follow-up care while accounting for repeated measures over time. ${ }^{16}$ Women with nine or more (70\% or higher) correct responses to the HPV knowledge index on any follow-up survey were considered to have adequate HPV knowledge. Women who reported they received follow-up diagnostic procedures and/or treatment on any follow-up survey were categorized accordingly.

\section{Results}

Table 1 presents the baseline demographic characteristics of Latinas who received the brochure intervention versus usual care. Women in both arms of the trial were comparable in age, birthplace, amount of time lived in the United States, language used to complete the survey, educational level, and health insurance coverage. Nearly half of women in both groups were self-pay. Women randomized to receive the brochure intervention were significantly less likely to be married than women who received usual care $(\mathrm{p}=.03)$.

Table 2 presents HPV awareness, HPV vaccine awareness, and HPV knowledge, attitudes and beliefs reported at baseline. Just over $60 \%$ of women had heard of HPV or the HPV vaccine, and there was no difference in women who received the brochure intervention compared with women who received usual care. Similarly, there were low HPV knowledge, attitudes and beliefs overall, which did not differ between women who received the brochure intervention compared with women who received usual care. 


\section{Table 1.}

DEMOGRAPHIC CHARACTERISTICS OF LATINAS WHO RECEIVED THE BROCHURE INTERVENTION VERSUS USUAL CARE REPORTED DURING BASELINE SURVEY

\begin{tabular}{|c|c|c|c|c|c|}
\hline \multirow[b]{2}{*}{ Demographic characteristic } & \multicolumn{2}{|c|}{$\begin{array}{c}\text { Brochure } \\
\text { intervention } \\
(\mathbf{n}=186)\end{array}$} & \multicolumn{2}{|c|}{$\begin{array}{l}\text { Usual care } \\
\qquad(\mathrm{n}=187)\end{array}$} & \multirow[b]{2}{*}{ p-value } \\
\hline & $\mathbf{n}$ & $\%$ & $\mathbf{n}$ & $\%$ & \\
\hline \multicolumn{6}{|l|}{ Age (years) } \\
\hline $18-24$ & 72 & 38.7 & 72 & 38.5 & \multirow[t]{4}{*}{.96} \\
\hline $25-34$ & 74 & 39.8 & 78 & 41.7 & \\
\hline $35-44$ & 28 & 15.1 & 27 & 14.4 & \\
\hline $45-64$ & 12 & 6.5 & 10 & 5.4 & \\
\hline \multicolumn{6}{|l|}{ Birthplace } \\
\hline United States & 81 & 43.6 & 85 & 45.5 & \multirow[t]{2}{*}{.71} \\
\hline Mexico & 105 & 56.4 & 102 & 54.6 & \\
\hline \multicolumn{6}{|c|}{ Amount of time in United States (years) } \\
\hline$<2$ & 10 & 10.2 & 6 & 5.8 & \multirow[t]{7}{*}{.62} \\
\hline $2-5$ & 18 & 17.4 & 26 & 25.2 & \\
\hline $6-10$ & 23 & 22.5 & 21 & 20.4 & \\
\hline $11-15$ & 25 & 23.5 & 24 & 23.3 & \\
\hline $16-20$ & 15 & 15.3 & 12 & 11.7 & \\
\hline$>20$ & 12 & 11.2 & 14 & 13.6 & \\
\hline Missing & 4 & & 2 & & \\
\hline \multicolumn{6}{|l|}{ Language used to complete survey } \\
\hline English & 91 & 48.9 & 85 & 45.5 & \multirow[t]{2}{*}{.50} \\
\hline Spanish & 95 & 51.1 & 102 & 54.6 & \\
\hline \multicolumn{6}{|l|}{ Marital status } \\
\hline Unmarried & 72 & 38.7 & 49 & 26.2 & \multirow[t]{3}{*}{.03} \\
\hline Married/living with a partner & 84 & 45.2 & 95 & 50.8 & \\
\hline Divorced/widowed/separated & 30 & 16.1 & 43 & 23.0 & \\
\hline \multicolumn{6}{|l|}{ Educational level } \\
\hline Less than high school & 92 & 49.5 & 81 & 43.3 & \multirow[t]{3}{*}{.42} \\
\hline High school graduate & 56 & 30.1 & 59 & 31.6 & \\
\hline More than high school & 38 & 20.4 & 47 & 25.1 & \\
\hline \multicolumn{6}{|l|}{ Health insurance coverage } \\
\hline Private insurance & 8 & 4.7 & 13 & 7.8 & \multirow[t]{4}{*}{.48} \\
\hline Medicaid & 78 & 45.4 & 73 & 44.0 & \\
\hline Self-pay & 86 & 50.0 & 80 & 48.2 & \\
\hline Missing & 14 & & 21 & & \\
\hline
\end{tabular}


Table 2.

CHARACTERISTICS REGARDING HPV AMONG LATINAS WHO RECEIVED THE BROCHURE INTERVENTION VERSUS USUAL CARE REPORTED DURING BASELINE SURVEY

\begin{tabular}{|c|c|c|c|c|c|}
\hline \multirow[b]{2}{*}{ Characteristics of HPV } & \multicolumn{2}{|c|}{$\begin{array}{c}\text { Brochure } \\
\text { intervention } \\
(n=186)\end{array}$} & \multicolumn{2}{|c|}{$\begin{array}{l}\text { Usual care } \\
(\mathbf{n}=187)\end{array}$} & \multirow[b]{2}{*}{ p-value } \\
\hline & $\mathbf{n}$ & $\%$ & $\mathbf{n}$ & $\%$ & \\
\hline \multicolumn{6}{|l|}{ Heard about HPV } \\
\hline No & 79 & 42.5 & 65 & 34.8 & \multirow[t]{2}{*}{.13} \\
\hline Yes & 107 & 57.5 & 122 & 65.2 & \\
\hline \multicolumn{6}{|l|}{ Heard about HPV vaccine } \\
\hline No & 81 & 43.5 & 68 & 36.4 & \multirow[t]{2}{*}{.16} \\
\hline Yes & 105 & 56.5 & 119 & 63.6 & \\
\hline \multicolumn{6}{|l|}{ HPV knowledge index } \\
\hline $0-8$ & 95 & 51.1 & 90 & 48.1 & \multirow[t]{2}{*}{.57} \\
\hline $9-13$ & 91 & 48.9 & 97 & 51.9 & \\
\hline \multicolumn{6}{|l|}{ HPV attitudes index } \\
\hline $0-9$ & 96 & 52.2 & 107 & 57.5 & \multirow[t]{3}{*}{.30} \\
\hline $10-15$ & 88 & 47.8 & 79 & 42.5 & \\
\hline Missing & 2 & & 1 & & \\
\hline \multicolumn{6}{|l|}{ HPV beliefs index } \\
\hline $0-6$ & 109 & 58.6 & 94 & 50.5 & \multirow[t]{3}{*}{.12} \\
\hline $7-10$ & 77 & 41.4 & 92 & 49.5 & \\
\hline Missing & 0 & & 1 & & \\
\hline
\end{tabular}

Table 3 presents patient recall of follow-up diagnostic procedures, treatment, and recommendations reported at baseline by receipt of the brochure intervention versus usual care. High percentages of women reported they were told to undergo follow-up diagnostic procedures (96.3\% for colposcopy/biopsy, $87.1 \%$ for repeat Pap test) which did not differ by receipt of the brochure intervention or usual care. Only one-fourth of women $(25.8 \%)$ indicated they were told to undergo cryotherapy/other treatment and a very small percentage of women reported they were told to "use a medicine to get rid of warts on the outside of your vagina" (9.3\%) with neither differing by receipt of the brochure intervention or usual care. The proportions of women reporting specific recommendations ranged from $57 \%$ for "stop having sex" to $69 \%$ for "don't douche." The percentage of women indicating they were told to "tell your partner that you have HPV" was significantly lower among women who received the brochure intervention $(58.1 \%)$ than among women who received usual care $(76.2 \%)(\mathrm{p}=.0002)$. Although the difference was not significant, a lower percentage of the women who received the brochure intervention than who received usual care indicated they were told at baseline to "use condoms every time you have sex." 


\section{Table 3.}

PATIENT RECALL OF RECOMMENDED FOLLOW-UP CARE OF LATINAS WHO RECEIVED THE BROCHURE INTERVENTION VERSUS USUAL CARE REPORTED DURING BASELINE SURVEY

\begin{tabular}{|c|c|c|c|c|c|}
\hline \multirow[b]{2}{*}{ Follow-up care } & \multicolumn{2}{|c|}{$\begin{array}{c}\text { Brochure } \\
\text { intervention } \\
(\mathbf{n}=\mathbf{1 8 6})\end{array}$} & \multicolumn{2}{|c|}{$\begin{array}{l}\text { Usual care } \\
(n=187)\end{array}$} & \multirow[b]{2}{*}{ p-value } \\
\hline & $\mathbf{n}$ & $\%$ & $\mathbf{n}$ & $\%$ & \\
\hline \multicolumn{6}{|c|}{ Self-report of diagnostic procedures } \\
\hline \multicolumn{6}{|c|}{ Colposcopy/biopsy } \\
\hline No & 8 & 4.3 & 6 & 3.2 & .58 \\
\hline Yes & 178 & 95.7 & 181 & 96.8 & \\
\hline \multicolumn{6}{|l|}{ Repeat Pap test } \\
\hline No & 24 & 12.9 & 24 & 12.8 & .98 \\
\hline Yes & 162 & 87.1 & 163 & 87.2 & \\
\hline \multicolumn{6}{|c|}{ Self-report of treatment } \\
\hline \multicolumn{6}{|c|}{ Cryotherapy/other treatment } \\
\hline No & 132 & 71.0 & 144 & 77.4 & .16 \\
\hline Yes & 54 & 29.0 & 42 & 22.6 & \\
\hline Missing & 0 & & 1 & & \\
\hline \multicolumn{6}{|l|}{ Treat warts } \\
\hline No & 167 & 90.8 & 164 & 90.6 & .96 \\
\hline Yes & 17 & 9.2 & 17 & 9.4 & \\
\hline Missing & 2 & & 6 & & \\
\hline \multicolumn{6}{|c|}{ Self-report of recommendations } \\
\hline \multicolumn{6}{|l|}{ Don’t douche } \\
\hline No & 57 & 31.0 & 55 & 30.0 & .85 \\
\hline Yes & 127 & 69.0 & 128 & 70.0 & \\
\hline Missing & 2 & & 4 & & \\
\hline \multicolumn{6}{|c|}{ Tell your partner you have HPV } \\
\hline No & 78 & 41.9 & 44 & 23.8 & .0002 \\
\hline Yes & 108 & 58.1 & 141 & 76.2 & \\
\hline Missing & 0 & & 2 & & \\
\hline \multicolumn{6}{|l|}{ Use condoms } \\
\hline No & 72 & 38.7 & 56 & 30.1 & .08 \\
\hline Yes & 114 & 61.3 & 130 & 69.9 & \\
\hline Missing & 0 & & 1 & & \\
\hline \multicolumn{6}{|l|}{ Don't smoke } \\
\hline No & 82 & 44.6 & 70 & 37.4 & .16 \\
\hline Yes & 102 & 55.6 & 117 & 62.6 & \\
\hline Missing & 2 & & 0 & & \\
\hline \multicolumn{6}{|c|}{ Stop having sex } \\
\hline No & 83 & 44.9 & 76 & 40.9 & .44 \\
\hline Yes & 102 & 55.1 & 110 & 59.1 & \\
\hline Missing & 1 & & 1 & & \\
\hline
\end{tabular}


Table 4.

KNOWLEDGE OF HPV AND RECEIPT OF FOLLOW-UP CARE OF LATINAS WHO RECEIVED THE BROCHURE INTERVENTION VERSUS USUAL CARE REPORTED DURING FOLLOW-UP SURVEY(S)

\begin{tabular}{|c|c|c|c|c|c|c|}
\hline \multirow[b]{2}{*}{ Characteristic } & \multicolumn{2}{|c|}{$\begin{array}{l}\text { Brochure } \\
\text { intervention } \\
(\mathbf{n}=186)\end{array}$} & \multicolumn{2}{|c|}{$\begin{array}{c}\text { Usual care } \\
(\mathbf{n}=\mathbf{1 8 7})\end{array}$} & \multirow[b]{2}{*}{$\mathbf{R R}^{\mathbf{a}}$} & \multirow[b]{2}{*}{$95 \% \mathrm{CI}^{\mathrm{b}}$} \\
\hline & $\mathbf{n}$ & $\%$ & $\mathbf{n}$ & $\%$ & & \\
\hline \multicolumn{7}{|c|}{ HPV knowledge index ${ }^{c}$} \\
\hline Inadequate & 7 & 3.8 & 9 & 4.8 & 1.00 & referent \\
\hline Adequate & 178 & 96.2 & 178 & 95.2 & 1.08 & $0.81-1.45$ \\
\hline Missing & 1 & & 0 & & & \\
\hline \multicolumn{7}{|l|}{ Follow-up care ${ }^{\mathrm{d}}$} \\
\hline No & 60 & 32.4 & 59 & 31.7 & 1.00 & referent \\
\hline Yes & 125 & 67.6 & 127 & 68.3 & 0.95 & $0.74-1.23$ \\
\hline Missing & 1 & & 1 & & & \\
\hline \multicolumn{7}{|c|}{$\begin{array}{l}{ }^{\text {a }} \text { Rate ratio adjusted for marital status. } \\
\text { bConfidence interval. } \\
\text { cAt least one follow-up survey with } 9 \text { or more correct responses to knowledge index. } \\
\text { dSelf-reported receipt of follow-up diagnostic procedures and/or treatment. }\end{array}$} \\
\hline
\end{tabular}

Table 4 presents the association between receipt of the brochure intervention versus usual care and self-reported knowledge of HPV and receipt of follow-up care reported at follow-up. Nearly all women had reported 9 or more correct responses to the HPV knowledge index during one or more follow-up surveys. Only two-thirds of women reported they had received follow-up care within one year of diagnosis. After adjustment for marital status, there was little effect of the brochure intervention on knowledge of HPV (RR 1.08, 95\% CI 0.81-1.45) or receipt of follow-up care (RR 0.95, 95\% CI 0.74-1.23).

\section{Discussion}

Although the participants in our study had been diagnosed with high-risk HPV, at baseline almost $40 \%$ indicated they had not heard of HPV or the HPV vaccine, and had correspondingly low levels of HPV knowledge, attitudes and beliefs. In a study of 215 HPV negative women we conducted from April 2007 to April 2008, similar percentages reported they had not heard of HPV $(39.1 \%)$ or the HPV vaccine $(42.1 \%) .{ }^{17}$ This lack of HPV awareness has also been found among Latina immigrants in Birmingham, Alabama. ${ }^{18}$

The high proportion of women who had not heard of HPV or the HPV vaccine may 
have been due to ineffective provider-patient communication. Effective provider-patient communication is important in delivering challenging information. Talking with patients about how their own or their partners' sex lives have increased their risk of cancer in this bilingual border population with traditional sex roles challenges providers and patients. To determine how providers communicated with their patients, we conducted in-depth provider interviews, which covered communication with women who have an abnormal Pap test/high-risk HPV diagnosis, perception of patients' reaction to an abnormal Pap test/high-risk HPV diagnosis, perception of patients' understanding of HPV, and HPV patient educational materials used with 26 providers of women's health care (74.3\% response rate). Most providers reported they informed female patients of their HPV status by telling them they had a "sexually transmitted infection that may cause cervical cancer." Women may not hear the entire message after having a highly personal reaction to being told they have a sexually transmitted infection, and wonder why they are returning for results of an abnormal Pap which might mean cancer. Starting the provision of this information with how common HPV is may ease the patients into the idea, allowing them to hear the accurate (yet alarming) information providers may give.

Nearly all participants reported they were told at baseline to receive follow-up care. Results from our in-depth provider interviews verified that the vast majority of providers recommended follow-up diagnostic procedures and treatments, and many providers also recommended their patients "practice safe sex, including condoms" and "stop smoking." Although a majority of participants reported they were told "don't douche" and "stop having sex," no providers indicated they had recommended against douching or having sex. Of concern is the substantially lower percentage of participants who received the brochure intervention than usual care who reported they were not told to "tell your partner that you have HPV" or "use condoms every time you have sex." The question of partner disclosure was not asked of providers specifically; however, it is inconceivable that providers would not inform patients to tell their partners of their diagnosis. The possible confusion about provider recommendations was noted by some providers who "recognized challenges to effectively communicating with patients at their level."

The percentage of patients whose HPV knowledge was classified as inadequate decreased from $49.6 \%$ at baseline to $4.3 \%$ at follow-up. The more surveys a participant completed the more likely she was to correctly respond to nine or more HPV knowledge questions from our index. Of the 16 participants whose HPV knowledge was classified as inadequate at follow-up, one had completed three follow-up surveys, five had completed two follow-up surveys, and 10 had completed one follow-up survey. Thus, as has been seen in other studies, ${ }^{19}$ the act of completing a survey(s) served as an educational intervention with regard to HPV knowledge.

Only two-thirds of participants reported they had received follow-up care within one year of diagnosis. As was the case with HPV knowledge, the more surveys a participant completed the more likely she was to report having received follow-up care. Of the 373 participants included in the present analysis, 191 completed three follow-up surveys (51.2\%), 111 completed two follow-up surveys (29.8\%), and 71 completed one follow-up survey (19.0\%). Some participants who completed the three-month follow-up survey only may have done so prior to their follow-up diagnostic appointment. 
Non-adherence to a follow-up care plan following an abnormal Pap test may result from a complex combination of emotional, cultural, socioeconomic and logistical factors. ${ }^{20}$ In a systematic review of 26 studies that investigated risk factors for nonadherence, primary barriers included lesion severity and health beliefs. ${ }^{21}$ Women whose lesions were less severe were less likely to adhere to follow-up care plans. ${ }^{22,23} \mathrm{In}$ a multiethnic study, Nelson et al. ${ }^{24}$ identified fatalistic health beliefs and misconceptions about cancer, such as the need for Pap tests following abnormal bleeding only, as risk factors for non-adherence among Spanish-speaking Latinas and Asians. Once the investigators controlled for these factors, there was no association between race/ethnicity and nonadherence. Two studies that did not control for health beliefs, reported that Latinas were less likely to adhere to follow-up recommendations than non-Hispanic White ${ }^{22}$ and African American ${ }^{23}$ women. We did not examine fatalistic health beliefs in any of our formative research, but misconceptions about cancer were prevalent in our study (anecdotal evidence). Socioeconomic status may have accounted for some women's failure to receive follow-up care, but self-pay women who qualified for the Texas Breast and Cervical Cancer Screening Program would have been covered by the program.

Lindau et al. ${ }^{25}$ identified physician estimates of low health literacy as a barrier to adherence to a care plan following an abnormal Pap test. Evaluations of printed HPV $(n=21)$ and cervical cancer prevention $(n=69)$ educational materials designed to enhance patient knowledge and awareness found that most materials had readability levels higher than 8th grade and low suitability. ${ }^{26-28}$ Brandt et al ${ }^{26}$ also identified poor HPV content for the majority of HPV educational materials; however, the brochure utilized in the present analysis was not included in the evaluation. HPV educational materials may be especially problematic for Latinas. Hunter ${ }^{29}$ examined written cervical cancer educational materials $(n=22)$ utilized with first-generation Mexican women in Kansas City and found that language was problematic, in addition to readability, suitability, and content. Over half of the women in our study completed the interview in Spanish; although the HPV brochure was translated into Spanish it may not have been tailored to the cultural needs of these women.

Our study has limitations. We restricted our analysis to Latinas who had completed at least one follow-up survey, the response rate to our 12-month follow-up survey was low, self-reported receipt of follow-up care is prone to misclassification, and there was potential contamination across intervention groups. Although our restriction reduced our sample by $19 \%$, we found similar results when we compared baseline characteristics of all 460 participants with the 373 women included in the present study. Our response rate for the 12 -month follow-up survey of $55 \%$ was primarily due to the $43 \%$ of participants who had not been followed a sufficient amount of time. The demographic and other baseline characteristics of women who were not followed a full year were similar to those of women who were followed for that period of time. The HPV knowledge, attitudes, and beliefs scales/subscales were developed through formative research and were not quantitatively validated.

Self-reported participation in cancer screening has shown "dependable agreement" with provider report, medical records review, and health insurance claims data. ${ }^{30,31} \mathrm{We}$ conducted a validation sub-study of self-reported diagnostic procedures at follow-up and calculated sensitivity and specificity using the medical record as the gold standard. 
While repeat Pap test had the highest sensitivity (87.1), it had the lowest specificity (39.7). We found moderate sensitivity and specificity for colposcopy (sensitivity 58.1, specificity 65.0) and biopsy (sensitivity 76.5, specificity 72.4). Medical records were collected approximately 3 months following the diagnosis so participants who received follow-up care subsequent to that time were not captured in the medical record. This may help explain the low specificity for repeat Pap test, but not the moderate sensitivity and specificity for colposcopy and biopsy.

There was a potential contamination effect since the HPV brochure and other sources of information may have been available to women in the usual care arm. Some providers responded they used HPV patient educational materials from Krames, Planned Parenthood, CDC, American College of Obstetricians and Gynecologists, Merck, and county health departments. The majority of participating providers were not sure of the publisher of the HPV patient educational materials they used. As noted previously, each survey a woman completed could be considered an educational intervention even though the HPV brochure was distributed only at baseline.

Study strengths include the population, and the use of information collected from providers and medical records to aid in the interpretation of results. Latinas living on the Texas-Mexico border have a high prevalence of abnormal Pap tests making the present study one of the largest studies of this topic. Few studies of follow-up care among Latinas have utilized information from providers in conjunction with information from patients. In addition, this is one of the first studies to determine the validity of reporting of follow-up care after abnormal Pap test conducted among Latinas that utilized medical records.

One of the possible explanations for the cervical cancer disparity among Latinas relative to other ethnic groups is the failure to follow the prescribed recommendation after an abnormal Pap test. Our findings suggest that although Latinas living on the Texas-Mexico border are aware that follow-up care is recommended they may not receive this care. Individual, family and medical care barriers to receipt of follow-up care may partially account for higher rates of cervical cancer mortality in this region.

This failure to receive follow-up care did not differ in women who received the brochure intervention or usual care, perhaps because the brochure's readability, suitability, HPV content and/or language were inappropriate for the population targeted, or because both groups of patients could be considered compliant since they were in the system and returning for counseling. A study of 44 low-income, high-risk HPV positive women found they preferred information written in an easily understood language, but their most trusted source of information was face-to-face with their health care provider. ${ }^{32}$ It is likely that to increase follow-up, these women may require more than educational materials. Other studies have shown that follow-up and time to follow-up improves with patient navigation. ${ }^{33} \mathrm{~A}$ study of obstetricians and gynecologists reported low physician adherence to current cervical cancer screening guidelines. ${ }^{34}$ Multi-level intervention approaches that target provider communication, organization change (such as reminder systems) as well as patient education are likely needed ${ }^{35}$ to reduce the elevated cervical cancer mortality among Latinas living on the Texas-Mexico border.

In conclusion, although our study is somewhat dated, the problem of cervical can- 
cer incidence and mortality on the Texas-Mexico border persists evidenced by having among the highest rates in Texas. ${ }^{7}$ Additional research is needed to examine the role of health care access, lack of health care coverage, and other social and environmental factors such as abusive/interfering partners and job and family responsibilities that may contribute to reduced participation in follow-up care.

\section{Acknowledgments}

This research was supported by grant number P20 MD000170 from the National Institute on Minority Health and Health Disparities. The authors would like to thank Concepcion Diaz Arrastia, Katherine S. Eggleston, Cheryl Olson, Lisa Mitchell-Bennett, Alice Gonzalez, Richard O. White, and Green Ekadi for their assistance with the project.

\section{References}

1. Munoz N, Castellsague X, de Gonzalez AB, et al. HPV in the etiology of human cancer. Vaccine. 2006 Aug 31;24 Suppl 3:S3/1-10. Epub 2006 Jun 23.

2. Howlader N, Noone AM, Krapcho M, et al., eds. SEER Cancer Statistics Review, 1975-2009. Bethesda, MD: National Cancer Institute, 2012.

3. Jemal A, Simard EP, Dorell C, et al. Annual Report to the Nation on the Status of Cancer, 1975-2009, featuring the burden and trends in human papillomavirus (HPV)associated cancers and HPV vaccination coverage levels. J Natl Cancer Inst. 2013 Feb 6;105(3):175-201. Epub 2013 Jan 7.

http://dx.doi.org/10.1093/jnci/djs491

PMid:23297039 PMCid:PMC3565628

4. American Cancer Society. Cancer Facts \& Figures 2015. Atlanta, GA: American Cancer Society, 2015. Available at: http://www.cancer.org/research/cancerfactsstatistics /cancerfactsfigures2015/.

5. Howe HL, Wu X, Ries LA, et al. Annual report to the nation on the status of cancer, 1975-2003, featuring cancer among U.S. Hispanic/Latino populations. Cancer. 2006 Oct 15;107(8):1711-42.

http://dx.doi.org/10.1002/cncr.22193

PMid:16958083

6. International Agency for Research on Cancer. Cervix cancer screening. Lyon, France: International Agency for Research on Cancer, 2005.

7. Cervical Cancer in Texas: A closer look. Austin, TX: Cancer Prevention \& Research Institute of Texas, 2012.

8. Coughlin SS, Uhler RJ, Richards T, et al. Breast and cervical cancer screening practices among Hispanic and non-Hispanic women residing near the United States-Mexico border, 1999-2000. Fam Community Health. 2003 Apr-Jun;26(2):130-9.

http://dx.doi.org/10.1097/00003727-200304000-00006

PMid:12802118

9. Greenberg H, Duarte-Gardea M, Quezada OR. Implications regarding atypical squamous cells of undetermined significance among women residing in a US-Mexico border city. Int J Gynecol Cancer. 2006 May-Jun;16(3):1014-6.

http://dx.doi.org/10.1111/j.1525-1438.2006.00597.x

PMid:16803478 
10. Rosenstock I, Strecher VJ, Becker MH. Social learning theory and the Health Belief Model. Health Educ Q. 1988 Summer;15(2):175-83.

http://dx.doi.org/10.1177/109019818801500203

PMid:3378902

11. Bandura A. Self-efficacy toward unifying theory of behavior change. Psychol Rev. 1977 Mar;84(2):191-215.

http://dx.doi.org/10.1037/0033-295X.84.2.191

PMid:847061

12. Bandura A. Social learning theory. Englewood Cliffs, NJ: Prentice Hall, 1977.

13. Ogilvy Public Relations Worldwide. Human papillomavirus creative materials testing, target audience focus group research final report. Atlanta, GA: Centers for Disease Control and Prevention, 2005. Available at: http://www.cdc.gov/std/Hpv /genaud4-2005/MaterialsTestingReportGenAud4-2005.pdf.

14. McCurdy SA, Fernandez ME, Arvey S, et al. Hispanic women's concerns about disclosure of their HPV+ status. Hisp Health Care Int. 2011;9(4):168-73.

http://dx.doi.org/10.1891/1540-4153.9.4.168

15. Fernandez ME, McCurdy SA, Arvey SR, et al. HPV knowledge, attitudes and cultural beliefs among Hispanic men and women living on the Texas-Mexico border. Ethn Health. 2009 Dec;14(6):607-24.

http://dx.doi.org/10.1080/13557850903248621

PMid:19953392 PMCid:PMC2874420

16. Liang KY, Zeger SL. Longitudinal data analysis using generalized linear models. Biometrika. 1986 Apr;73(1):13-22. Available at: http://www.biostat.jhsph.edu/ fdominic /teaching/bio655/references/extra/liang.bka.1986.pdf.

http://dx.doi.org/10.1093/biomet/73.1.13

17. Sanderson M, Coker AL, Eggleston KS, et al. HPV vaccine acceptance among Latina mothers by HPV status. J Womens Health (Larchmt). 2009 Nov;18:1793-9. http://dx.doi.org/10.1089/jwh.2008.1266 PMid:19951213 PMCid:PMC2828161

18. Drewry J, Garces-Palacio IC, Scarinci I. Awareness and knowledge about human papillomavirus among Latina immigrants. Ethn Dis. 2010 Autumn;20(4):327-33. PMid:21305817 PMCid:PMC3097024

19. Scarinci IC, Garcia FAR, Kobetz E, et al. Cervical cancer prevention: new tools and old barriers. Cancer. 2010 Jun 1;116(11):2531-42.

http://dx.doi.org/10.1002/cncr.25065

20. Khanna N, Phillips MD. Adherence to care plan in women with abnormal Papanicolaou smears: a review of barriers and interventions. J Am Board Fam Pract. 2001 Mar-Apr;14(2):123-30.

PMid:11314919

21. Eggleston KS, Coker AL, Prabhu Das I, et al. Understanding barriers for adherence to follow-up care for abnormal pap tests. J Womens Health (Larchmt). 2007 Apr;16(3):311-30.

http://dx.doi.org/10.1089/jwh.2006.0161

PMid:17439377

22. Fox $\mathrm{P}$, Amsberger $\mathrm{P}$, Zhang $\mathrm{X}$. An examination of differential follow-up rates in cervical cancer screening. J Community Health. 1997 Jun;22(3):199-209.

http://dx.doi.org/10.1023/A:1025125124926

PMid:9178119 
23. Marcus AC, Crane LA, Kaplan CP, et al. Improving adherence to screening follow-up among women with abnormal Pap smears: results from a large clinic-based trial of three intervention strategies. Med Care. 1992 Mar;30(3):216-30.

http://dx.doi.org/10.1097/00005650-199203000-00004

PMid:1538610

24. Nelson K, Geiger AM, Mangione CM. Effect of health beliefs on delays in care for abnormal cervical cytology in a multiethnic population. J Gen Intern Med. 2002 Sep;17(9):709-16.

http://dx.doi.org/10.1046/j.1525-1497.2002.11231.x

PMid:12220368 PMCid:PMC1495105

25. Lindau ST, Basu A, Leitsch SA. Health literacy as a predictor of follow-up after an abnormal Pap smear: a prospective study. J Gen Intern Med. 2006 Aug;21(8):829-34. http://dx.doi.org/10.1111/j.1525-1497.2006.00534.x PMid:16881942 PMCid:PMC1831576

26. Brandt HM, McCree DH, Lindley LL, et al. An evaluation of printed HPV educational materials. Cancer Control. 2005 Nov;12 Suppl 2:103-6.

27. Helitzer D, Hollis C, Cotner J, et al. Health literacy demands of written health information materials: an assessment of cervical cancer prevention materials. Cancer Control. 2009 Jan;16:70-8.

28. Roland KB, Benard VB, Saraiya M, et al. Assessing cervical cancer screening guidelines in patient education materials. J Womens Health (Larchmt). 2009;18:5-12. http://dx.doi.org/10.1089/jwh.2008.1211

29. Hunter JL. Cervical cancer educational pamphlets: Do they miss the mark for Mexican immigrant women's needs? Cancer Control. 2005 Nov;12 Suppl 2:42-50.

30. Jones RM, Mongin SJ, Lazovich D, et al. Validity of four self-reported colorectal cancer screening modalities in a general population: differences over time and by intervention assignment. Cancer Epidemiol Biomarkers Prev. 2008 Apr;17(4):777-84. Epub 2008 Apr 1.

http://dx.doi.org/10.1158/1055-9965.EPI-07-0441

PMid:18381476

31. Partin MR, Grill J, Noorbaloochi S, et al. Validation of self-reported colorectal cancer screening behavior from a mixed-mode survey of veterans. Cancer Epidemiol Biomarkers Prev. 2008 Apr;17(4):768-76. Epub 2008 Apr 1.

http://dx.doi.org/10.1158/1055-9965.EPI-07-0759

PMid:18381474

32. McCree DH, Sharpe PA, Brandt HM, et al. Preferences for sources of information about abnormal Pap tests and HPV in women tested for HPV. Prev Med. 2006 Sep;43(3):165-70. Epub 2006 May 15.

http://dx.doi.org/10.1016/j.ypmed.2006.04.001

PMid:16701815

33. Ramirez AG, Penedo FJ, Pérez-Stable EJ, et al. Navigating Latinas with breast screen abnormalities to diagnosis: the Six Cities Study. Cancer. 2013 Apr 1;119(7):1298-305. Epub 2012 Dec 10.

http://dx.doi.org/10.1002/cncr.27912

PMid:23233265 PMCid:PMC3628781

34. Perkins RB, Anderson BL, Sheinfeld Gorin S, et al. Challenges in cervical cancer prevention: a survey of U.S. Obstetricians-Gynecologists. Am J Prev Med. 2013 Aug;45(2):175-81. 
http://dx.doi.org/10.1016/j.amepre.2013.03.019

PMid:23867024

35. Taplin SH, Price RA, Edwards HM, et al. Introduction: Understanding and influencing multilevel factors across the cancer care continuum. J Natl Cancer Inst Monogr. 2012 May;2012(44):2-10.

http://dx.doi.org/10.1093/jncimonographs/lgs008

PMid:22623590 PMCid:PMC3482968 